\title{
Pelanggaran Prinsip Kerja Sama dalam Variety Show Jepang Gyouretsu no Dekiru Houritsu Soudanjo
}

\author{
Luh Komang Indrayani ${ }^{1 *}$, Ni Luh Kade Yuliani Giri ${ }^{2}$, Ni Made Andry Anita \\ Dewi $^{3}$ \\ ${ }^{[123]}$ Program Studi Sastra Jepang Fakultas Ilmu Budaya \\ ${ }^{1}$ [email:luhkomangindrayani18@gmail.com] [2 [email:giri222000@yahoo.com] \\ ${ }^{3}$ [email:andry_anita@unud.ac.id] \\ *Corresponding Author
}

\begin{abstract}
The research deals with The Violation of Cooperative Principle in Japanese Variety Show Gyouretsu no Dekkiru Houritsu Soudanjo. This research aims to identify types and function of the violation of cooperative principle in Japanese variety show gyouretsu no dekiru houritsu soudanjo. The theory used are cooperation principle (Grice, 1975) and speech acts theory (Searle, 1979). The data are collected using the method of referring by listening to the variety show and transcribing the data. This research is analyzed with padan pragmatic method.To present the result of data analysis using informal method. Based on the analysis, there are 20 forms of violation of cooperative principle. There are 7 data which violated the maxim of quantity, 4 data which violated the maxim of quality, 5 data which violated the maxim of relevance, 4 data which violated the maxim of manner, and 1 data which violated 2 maxim. There are, violated the maxim of quantity and violated the maxim of relevance. The purposes of violating cooperative principle in variety show gyouretsu no dekiru houritsu soudanjo consist 5 illocutionary speech acts. These purposes are 1) assertive: complaining, informing, lying, and enforcing; 2) directive: consenting, requesting, and ordering; 3) expressive: mocking, arrogant, joking, teasing, thanking, pardoning, deploring, ridiculing, and praising; 5) declarative: deciding, to say an opinion, and naming.
\end{abstract}

Keywords: pragmatic, cooperative principle, speech act

\begin{abstract}
Abstrak
Penelitian ini berjudul "Pelanggaran Prinsip Kerja Sama dalam Variety show Jepang Gyouretsu no Dekiru Houritsu Soudanjo". Tujuan dari penelitian ini adalah untuk mengetahui bentukbentuk pelanggaran prinsip kerja sama dan tujuan dari pelanggaran prinsip kerja sama dalam variety show Jepang Gyouretsu no Dekiru Houritsu Soudanjo. Penelitian ini menggunakan teori prinsip kerja sama yang dikemukakan oleh Grice (1975) dan teori tindak tutur yang dikemukakan oleh Searle (1979). Metode yang digunakan dalam mengumpulkan data adalah metode simak yaitu dengan mendengarkan variety show tersebut dan mentranskripsikan data. Pada analisis data digunakan metode padan dengan pendekatan pragmatik. Selanjutnya, dalam penyajian hasil analisis data menggunakan metode informal. Hasil penelitian menunjukkan bahwa dalam variety show Jepang Gyouretsu no Dekiru Houritsu Soudanjo, ditemukan 20 data yang melanggar prinsip kerja sama yaitu, terdapat 7 buah tuturan yang melanggar maksim kuantitas, 4 buah tuturan yang melanggar maksim kualitas, 5 buah tuturan yang melanggar maksim relevansi, 4 buah tuturan yang melanggar maksim pelaksanaan. Terdapat 1 data yang melanggar dua maksim yaitu, maksim kuantitas dan maksim relevansi. Selanjutnya, tujuan dari pelanggaran prinsip kerja sama dalam variety show Jepang Gyouretsu no Dekiru Houritsu Soudanjo terdiri dari 5 macam tindak tutur ilokusi yaitu, 1) tindak tutur ilokusi asertif: mengeluh, memberitahu, berbohong, dan memaksa; 2) tindak tutur ilokusi direktif: meminta
\end{abstract}


persetujuan, memohon, dan menyuruh; 3) tindak tutur ilokusi komisif: menolak; 4) tindak tutur ilokusi ekspresif: mengejek, sombong, bercanda, menyindir, berterima kasih, meminta maaf, menyesal, mengolok-olok, dan memuji; 5) tindak tutur ilokusi deklaratif: memutuskan, menyatakan pendapat, dan memberi julukan atau nama.

Kata Kunci: pragmatik, prinsip kerja sama, tindak tutur.

\section{(1) Latar Belakang}

Bahasa merupakan alat komunikasi yang memiliki peran penting dalam kehidupan masyarakat sehari-hari. Bahasa digunakan untuk menyampaikan ide, gagasan, maupun perasaan kepada orang lain, sehingga dengan adanya bahasa dapat memberikan kemudahan dalam melakukan komunikasi dan berinteraksi antar penutur dan mitra tutur. Akan tetapi, untuk mencapai suatu komunikasi dapat berjalan dengan baik diperlukan kerja sama antara penutur dan mitra tutur. Hal ini bertujuan untuk memeroleh informasi yang dapat dipahami dengan baik dan tidak bersifat ambigu. Apabila dalam suatu komunikasi terdapat tuturan yang bersifat ambigu, maka tuturan tersebut dikhawatirkan dapat melanggar prinsip kerja sama.

Prinsip kerja sama merupakan suatu bentuk kerja sama antara penutur dan mitra tutur yang bertujuan untuk mendapatkan informasi yang jelas dan terjalin komunikasi yang baik. Grice dalam bukunya Logic and Conversation (1975:45-47) menyatakan bahwa prinsip kerja sama terdiri dari empat macam yaitu, maksim kuantitas, maksim kualitas, maksim relevansi, dan maksim pelaksanaan.

Sumber data yang digunakan dalam penelitian ini adalah variety show Jepang yang berjudul Gyouretsu no Dekiru Houritsu Soudanjo. Variety show ini memiliki durasi sekitar 54 menit,dengan jumlah total lima buah episode yang tayang pada tahun 2017 dan telah diunduh sebelumnya. Pemilihan episode untuk sumber data dipilih secara acak atau tidak berurutan sesuai dengan tanggal penayangannya. Dalam variety show ini acara yang disajikan dikemas dengan suasanya santai dan dibarengi dengan lelucon-lelucon oleh pembawa acaranya. Lelucon yang disampaikan tersebut identik dengan tuturan yang sengaja dilakukan dan disampaikan secara tidak relevan. Artinya, terkadang penutur menyampaikan tuturan yang mengandung unsur lelucon tersebut membahas topik yang tidak sesuai dengan hal yang dibicarakan. Oleh karena itu, seringkali tuturan-tuturan yang mengandung lelucon cenderung melanggar prinsip kerja sama. Tuturantuturan tersebut disampaikan oleh penutur dalam suatu situasi yang bertujuan untuk menyindir, bercanda, mengejek dan sebagainya.

\section{(2) Pokok Permasalahan}

Berdasarkan latar belakang yang telah dipaparkan tersebut, masalah yang dibahas dalam penelitian ini dapat dirumuskan sebagai berikut.

a. Bagaimanakah bentuk pelang-garan prinsip kerja sama dalam variety show Jepang Gyouretsu no Dekiru Houritsu Soudanjo?

b. Bagaimanakah tujuan dari pelanggaran prinsip kerja sama dalam variety show Jepang Gyouretsu no Dekiru Houritsu Soudanjo?

\section{(3) Tujuan Penelitian}

Penelitian ini bertujuan untuk memberikan pengetahuan mengenai kajian pragmatik yaitu, mengenai pelanggaran prinsip kerja sama. Secara khusus, tujuan penelitian ini yaitu, untuk mengetahui bentuk-bentuk pelanggaran prinsip kerja sama dan tujuan 
pelanggaran prinsip kerja sama dalam variety show Jepang Gyouretsu no Dekiru Houritsu Soudanjo.

\section{(4) Metode Penelitian}

Metode pengumpulan data dalam penelitian ini adalah metode simak dengan teknik simak bebas libat cakap dan teknik catat (Sudaryanto, 2015:203205). Pada tahap analisis data, digunakan metode padan pragmatik (Sudaryanto, 2015:17-18). Selanjutnya pada tahap penyajian hasil analisis data digunakan metode informal. Teori yang digunakan untuk memecahkan permasalahan penelitian ini adalah teori prinsip kerja sama yang dikemukakan oleh Grice (1975) untuk menganalisis bentuk-bentuk pelanggaran prinsip kerja sama. Selanjutnya, teori tindak tutur ilokusi yang dikemukakan oleh Searle (1979) digunakan untuk menganalisis tujuan pelanggaran prinsip kerja sama variety show Jepang Gyouretsu no Dekiru Houritsu Soudanjo .

\section{(5) Hasil dan Pembahasan}

Pada bagian ini dijelaskan mengenai hasil analisis data dalam variety show Jepang Gyouretsu no Dekiru Houritsu Soudanjo. Terdapat 20 data tuturan yang melanggar prinsip kerja sama dalam variety show tersebut. Berikut merupakan hasil analisis data pelanggaran prinsip kerja sama beserta tujuannya dalam tindak tutur ilokusi.

\subsection{Pelanggaran Maksim Kuantitas \\ Maksim kuantitas merupakan} kaidah yang mengharapkan penutur dapat memberikan informasisebanyak yang dibutuhkan oleh mitra tutur.Kontribusi tersebut berupa informasi yang cukup, memadai dan tidak melebihkan informasi yang sesungguhnya (Grice, 1975:45-47).
（1）渡部建 ：謝らない時間が長す ぎますけど、まずぱ つと謝らないと。

伊藤英明：わかりました。三浦

友和さん大変貴重な

ウイスキーをありが

とうございました。

えー、とてもおいし

かつたです。それに、

添えていただいた手

紙読まずに捨ててし

まいした。すみませ

んでした。以上です。

渡部建 ：よそう以上にちゃん

と謝りましたね。

渡部建：すごい、ちやんと謝

りましたね。

後藤輝基：会場がキンキンに冷

えてましたよ。

「行列のできる法律相談所第三、

2017: 30:27-31:01 」

Watabe Ken : Ayamaranai jikan ga nagasugimase kedo, mazu patto ayaramanai.

Itou Hideaki : Wakarimashita,

Miura Tomokawasan taihen kichou na uisukii o arigatou gozaimashita.ee, totemo oishikatta desu. Sore ni, soete 


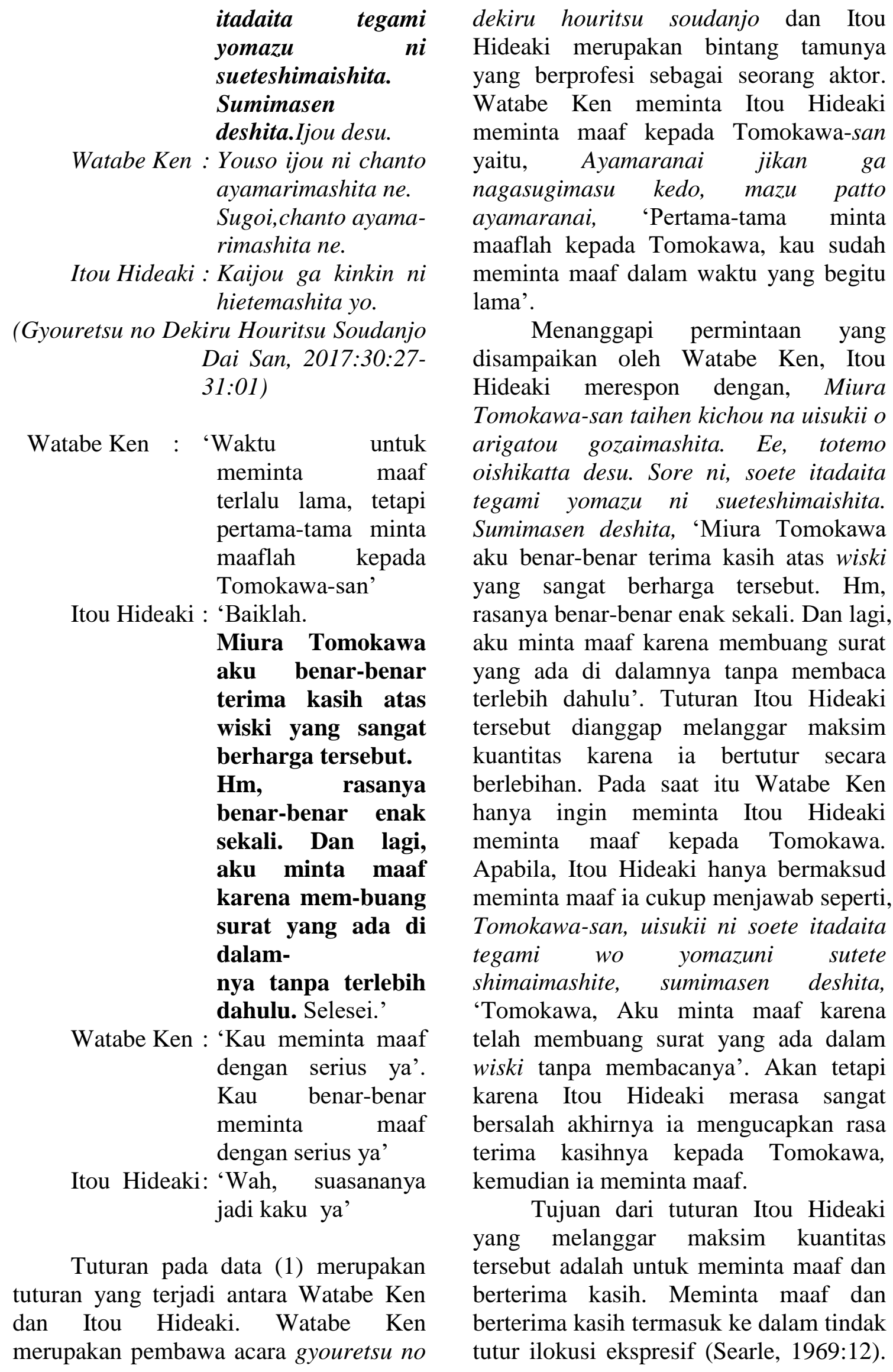


Pada tuturan Itou Hideaki terdapat ungkapan arigatou gozaimashita yang memiliki arti 'terima kasih'. Itou Hideaki mengunakan bentuk lampau pada ungkapan tersebut karena Tomokawa telah memberikannya sesuatu yang sangat berharga. Selanjutnya, pada tuturannya juga terdapat ungkapan sumimasen deshita, yang artinya 'saya meminta maaf', menunjukkan sikap Itou Hideaki ketika melakukan kesalahan kepada Tomokawa. Pada tuturan permintaan maaf Itou Hideaki terdapat pola kalimat shimau. Shimau merupakan verba bantu yang digunakan untuk menyatakan penyelesaian dari suatu tindakan yang digunakan untuk menyatakan suatu tindakan yang telah selesai, tetapi juga digunakan ketika menyatakan suatu penyesalan (Makino \& Tsutsui, 1989:403-405).

\subsection{Pelanggaran Maksim Kualitas}

Maksim kualitas merupakan maksim yang harus sesuai dengan fakta dan disertai bukti yang jelas. Grice (1975:45-47) menyatakan bahwa dalam maksim kualitas penutur diharapkan dapat mengungkapkan hal yang sebenarnya.

（2）藤原竜也 : あのさ、勘九郎 流血事件の真相

って、うかじさ んがやったんだ よ!

(にやっと わらう)

$$
\begin{array}{r}
\text { ともだち : そうなんです } \\
\text { か? 怖いつすね。 }
\end{array}
$$

ナレーター：冗談で、宇梶さ

んが犯人と言っ

てしまった。

「行列のできる法律

相談所第三、2017: 15:08-15:19」

Fujiwara Tatsuya : Ano sa,

kankurou

ryuuketsu jiken

no shinsoutte,

ukaji san ga

yattan day yo!

(niyatto warau)

Tomodachi : Sou nan desu ka?

Kowaissu ne.

Nareetaa : Joudan de, ukajisan ga hannin to itte shimatta.

(Gyouretsu no Dekiru Houritsu

Soudanjo Dai San, 2017:15:08-15:19)

Fujiwara Tatsuya :'Hei,sebenarnya
kasus berdarah
yangdialami
oleh Kankurou,
Ukajilah yang
melakukannya'
(menyeringai)
: 'Beneran? Wah,
dia menyeramkan
Teman
: 'Akibat lelucon
Narator
yang dibuatnya,
Ukaji dianggap
sebagai seorang
penjahat'

Tuturan pada data (2) merupakan tuturan yang terjadi antara Fujiwara Tatsuya dan temannya. Fujiwara Tatsuya memiliki profesi sebagai seorang aktor. Teman Fujiwara Tatsuya terkejut ketika mendengar informasi dari Fujiwara Tatsuya bahwa yang melukai Ukaji adalah Kankurou. Tuturan temannya 
yaitu, Sou nan desu ka? Kowaissu ne, 'Beneran?Wah dia menyeramkan ya'.

Tuturan Fujiwara Tatsuya yang mengatakan kebohongan terhadap Kankurou yaitu, Ano sa, Kankurou ryuuketsu jiken no shinsou tte, Ukaji-san ga yattan da yo!, 'Hei, sebenarnya kasus berdarah yang dialami oleh Kankurou, Ukajilah yang melakukannya'. Tuturan Fujiwara Tatsuya dianggap melanggar maksim kualitas karena ia bertutur tanpa memiliki bukti dan sesuai dengan fakta yang ada. Sebenarnya, Kankurou terluka ketika ia kembali dari toilet, karena terlalu mabuk dan secara tidak sengaja dagunya terbentur pada meja makan ketika hendak duduk. Seharusnya, Fujiwara Tatsuya mengatakan kejadian yang sebenarnya seperti, Kankurou wa tsukue no kado ni ago wo butsukemashita kara, ke ga wo shimashita yo, 'Kankurou terluka karena dagunya terbentur di sudut meja', agar tidak terjadi kesalahpahaman.

Tujuan dari tuturan Fujiwara Tatsuya yang melanggar maskim kualitas adalah untuk berbohong. Berbohong termasuk ke dalam tindak tutur ilokusi asertif (Searle, 1979:12). Fujiwara Tatsuya sebenarnya mengetahui kejadian yang menimpa Ukaji, akan tetapi ia mengatakan hal sebalikanya kepada temannya. Selain itu, ekspresi menyeringai yang ditunjukkan ketika Fujiwara Tatsuya mengatakan hal tersebut menunjukkan sebuah kesengajaan untuk berbohong. Hal ini menyebabkan beredarnya rumor buruk tentang Ukaji .

\subsection{Pelanggaran Maksim Relevansi}

Maksim relevansi mewajibkan penutur untuk memmberikan informasi yang relevan. Grice (1975:45-47) menyatakan bahwa maksim relevansi mewajibkan penutur untuk memberikan kontribusi yang relevan sesuai dengan situasi percakapan dan sesuai dengan topik yang dibahas.
(3)

$\begin{array}{cl}\text { 水谷豊 } & \text { はじめまして、 } \\ \text { チョーヒカル : ああ、摩を求める） } & \text { あ触ってい } \\ \text { いんですか? } \\ \text { (手を伸ばす) } \\ \text { ああ、録画 録 } \\ \text { あ画 録画お願い } \\ \text { します。 } \\ \text { (スタッフを }\end{array}$

見る)
東野幸治 ： どうですか水谷
さんこれ…
(body paint の真
を指す）、ある
くで見て ?
水谷豊 : いや、ネットで
拝見したこと
あるんですよ。

「行列のできる法律相談所第四、

2017:20:58-21:12」

$\begin{aligned} \text { Mizutani Yutaka } & \text { :Hajimemashite, } \\ \text { (akushuo } & \text { motomeru) }\end{aligned}$

Choo Hikaru : Aa, sawatte iin desu ka? (te o nobasu) Aa, kiroku, kiroku, kiroku onegaishimasu. (sutaffu o miru)

Higashino Kouji: Dou desuka?

Mizutani-san kore, (body paint no 


\section{shashin o sasu), aruku de mite? \\ Mizutani Yutaka: Iya, netto de haiken shita koto arun desu yo.}

(Gyouretsu no Dekiru Houritsu Soudanjo Dai Yon, 2017: 20:58-21:12)

\begin{tabular}{cl} 
Mizutani Yutaka: 'Salam kenal' & \multicolumn{1}{c}{ (menjabat tangan) } \\
Choo Hikaru & 'Ahh, bolehkan \\
& akumenyentuhn \\
& ya? \\
& (mengulurkan \\
& tangan juga) \\
& 'Aaa, tolong \\
& direkam' \\
& (melihat para staff \\
& gyouretsu) \\
Higashino Kouji : 'Bagaimana & menurut Anda \\
& tentang body \\
& paint ini?' \\
(menunjuk foto & body paint) \\
Mizutani Yutaka : 'Yah, aku pernah \\
melihatnya di \\
internet'
\end{tabular}

Tuturan pada data (3) merupakan tuturan yang terjadi antara Mizutani Yutaka dan Choo Hikaru.Mizutani Yutaka dan Choo Hikaru merupakan bintang tamu yang hadir dalam acara gyouretsu no dekiru houritsu soudanjo. Choo Hikaru diundang ke acara tersebut karena ia seorang artis body paint yang sangat menyukai Mizutani Yutaka. Ketika bertemu dengan Mizutani Yutaka secara langsung ia menjadi sangat senang, sehingga meminta para staff merekam mereka berdua. Tuturan Choo Hikaru yaitu, Aa, sawatte iin desu ka? (te o nobasu) Aa, kiroku, kiroku, kiroku onegaishimasu, 'Ahh, bolehkan aku menyentuhnya? (mengulurkan tangan juga)'Aaa, tolong direkam'. Tuturan Choo Hikaru dianggap melanggar maksim relevansi karena tuturan tersebut tidak memiliki keterkaitan antara tuturan yang diucapkan oleh Mizutani Yutaka. Padahal saat itu, Mizutani Yutaka hendak mengulurkan tangannya untuk memberi salam kepada Choo Hikaru, namun Choo Hikaru malah meminta staff untuk merekam mereka. Seharusnya, Choo Hikaru bertutur seperti, Hajimemashita, Choo Hikaru desu. Yoroshiku Onegaishimasu, Saya Choo Hikaru, salam kenal'.

Tujuan dari tuturan Choo Hikaru yang melanggar maksim relevansi adalah untuk memohon. Memohon termasuk ke dalam tindak tutur ilokusi direktif (Searle, 1979:13). Dilihat dalam tuturan tuturan Choo Hikaru terdapat kata onegaishimasu yang menunjukkan tujuan memohon. Dari permohonannya tersebut dimaksudkan agar ia memperoleh hasil rekaman antara ia dan Mizutani Yutaka.

\subsection{Pelanggaran Maksim Pelaksanaan}

Maksim pelaksanaan merupakan maksim yang harus memiliki kejelasan dan keruntutan dalam suatu tuturan. Grice (1975:45-47) menyatakan bahwa maksim pelaksanaan mengharuskan penutur berbicara dengan memberikan kontribusi yang jelas, tanpa ambigu, dan ringkas.

（4）満島の友人： 来週さ引つ越し 手伝つてくれよ。

$$
\begin{array}{ll}
\text { 満島真之介： } & \text { No!ファンタス } \\
& \text { ティック ! }
\end{array}
$$

満島の友人 : ...

$$
\text { (いらいらする) }
$$

ナレーター：「No!ファンタス

$$
\text { ティック!」 }
$$


といえば、相手

を傷つけずに済

むという。

「行列のできる法律相談所第二、

2017:28:07-28:17」

\section{Mitsushina no}

Yuujin

Raishuи sa

hikkoshi

tetsudatte kure yo.

Mitsushima

Shinosuke : No!

Fantasutekku!

Mitsushima no

Yuujin

Nareetaa

$$
\text { (ira ira suru) }
$$

"No
Fantasuttekku!"
ieba, aite
kizutsukezu
sumu to iu.

(Gyouretsu no Dekiru Houritsu Soudanjo

Dai Ni, 2017: 28:07-28:17)

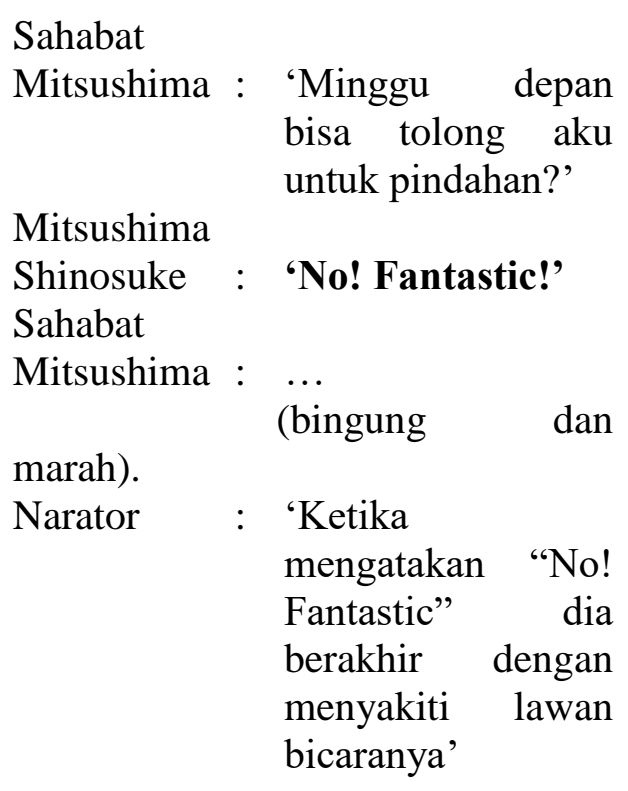

Tuturan pada data (4) merupakan tuturan yang terjadi antara sahabat Mitsushima dan Mitsushima Shinosuke. Mitsushima Shinosuke memiliki profesi sebagai seorang aktor. Tuturan terjadi ketika sahabat Mitsushima meminta tolong kepada Mitsushima Shinosuke untuk membantu pindah rumah yaitu, Raishuu sa hikkoshi tetsudatte kure yo, 'Minggu depan bantu aku pindahan rumah ya!'.

Menanggapi permintaan dari sahabatnya sendiri, Mitsushima Shinosuke merespon dengan No! Fantasutekku!, 'No Fantastic'. Tuturan Mitsushima Shinosuke dianggap melanggar maksim pelaksanaan karena ia bertutur secara tidak jelas. Sahabat Mitsushima meminta bantuan kepada Mitsushima Shinosuke untuk membantunya pindahan rumah, namun menolak permintaan sahabatnya dalam bahasa Inggris. Hal tersebut membuat sahabatnya kesal dan bingung karena Mitsushima Shinosuke secara terus terang menolak permintaannya. Seharusnya, Mitsushima Shinosuke menjawab seperti, etto, youji ga arimasu kara, chotto..., 'Maaf, saat itu aku ada urusan...'.

Tujuan dari tuturan Mitsushima Shinosuke yang melanggar maksim pelaksanaan adalah untuk menolak. Menolak termasuk ke dalam tindak tutur ilokusi komisif (Searle, 1979:14). Sikap Mitsushima Shinosuke tidak menggambarkan sikap seperti orang Jepang yang jarang menyatakan suatu hal secara langsung dan jelas. Osamu (2002:11) menjelaskan bahwa di Jepang orang-orang yang bermaksud untuk menolak permintaaan mitra tuturnya akan menggunakan ungkapan yang tidak langsung seperti, chotto, demo, agar tidak menyinggung perasaan mitra tuturnya.

\section{(6) Simpulan}

Berdasarkan data yang telah dianalisis terdapat 20 data yang melanggar prinsip kerja sama dalam variety show Jepang gyouretsu no dekiru houritsu soudanjo. Adapun data-data tersebut yaitu, 7 buah tuturan yang 
melanggar maksim kuantitas, 4 buah tuturan yang melanggar maksim kualitas, 5 buah tuturan yang melanggar maksim relevansi, dan 4 buah tuturan yang melanggar maksim pelaksanaan. Di antara 20 buah tuturan tersebut terdapat 1 buah data yang melanggar lebih dari satu maksim yaitu, melanggar maksim kuantitas dan maksim relevansi.

Berikut adalah tujuan pelanggaran prinsip kerja sama dalam variety show tersebut, (1) tujuan dari pelanggaran prinsip kerja sama berdasarkan tindak tutur ilokusi asertif yaitu, mengeluh, memberitahu, berbohong, dan memaksa. (2) Tujuan dari pelanggaran prinsip kerja sama berdasarkan tindak tutur ilokusi direktif yaitu, meminta persetujuan, memohon, dan menyuruh. (3) Tujuan dari pelanggaran prinsip kerja sama berdasarkan tindak tutur ilokusi komisif yaitu, menolak. (4) Tujuan dari pelanggaran prinsip kerja sama berdasarkan tindak tutur ilokusi ekspresif yaitu, mengejek, menyombongkan diri, bercanda, menyindir, berterima kasih, meminta maaf, menyesal, mengolok-olok, dan memuji. (5) Tujuan dari pelanggaran prinsip kerja sama berdasarkan tindak tutur ilokusi deklaratif yaitu, memutuskan, menyatakan pendapat, dan memberi nama atau julukan. Terdapat 1 data yang memiliki 2 tujuan dalam satu tuturan yang melanggar prinsip kerja sama yaitu

bertujuan untuk berterima kasih dan meminta maaf. Tujuan dalam pelanggaran prinsip kerja sama dalam variety show tersebut tidak hanya berdasarkan pada bentuk pola kalimat yang digunakan seperti te shimau, adanya partikel akhir na, dan ne, juga dipengaruhi oleh budaya Jepang yaitu aimai bunka.

\section{(7) Daftar Pustaka}

Chino, Naoko. 1991. All About Particles

A Handbook of Japanese

unction.Tokyo: Kodansha

International.

Grice, H.P. 1975. Logic and Conversation. New York: Oxford University Press.

Osamu, Ikeno. 2002. The Japanese Mind. Tokyo: Tuttle Publishing.

Searle, Jhon.R. 1979. Epression And Meaning:Studies in The Theory of Speech Act. New York: Cambridge University Press.

Sudaryanto. 2015. Metode dan Aneka Teknik Analisis Bahasa. ogyakarta: Universitas Sanata Dharma nggota APPTI. 